\title{
Substrate specificity of the Trypanosoma cruzi trans-sialidase
}

\author{
Filip Vandekerckhove, Sergio Schenkman', Lain Pontes \\ de Carvalho, Stephen Tomlinson, Makoto Kiso', \\ Masahiro Yoshida ${ }^{2}$, Akira Hasegawa ${ }^{2}$ and \\ Victor Nussenzweig
}

Michael Heidelberger Division of Immunology, Department of Pathology (MSB 130), New York University Medical Center, 550 First Avenue, New York, NY 10016, USA, 'Disciplina de Bюlogıa Celular, Escola Paulista de Medicina, Sao Paulo, Brazil and ${ }^{2}$ Department of Applied Bıorganic Chemistry, Gifu University, Gifu 501-11, Japan

Trypanosoma cruzi trypomastigotes acquire sialic acid (SA) from host glycoconjugates by means of a plasma membraneassociated trans-sialidase (TS). Here we study the substrate specificity of TS, which differs from all known sialyltransferases in that it does not require cytidine monophosphate (CMP)-SA as donor. The T.cruzi TS reversibly transfers SA to saccharides with terminal $\beta$-Gal (but not $\alpha$-Gal) residues. Donors are saccharides with SA linked to terminal $\beta$-Gal residues by $(\alpha 2-3)$, but not $(\alpha 2-6)$ bonds. The type of $\beta$-linkage of the terminal $\mathrm{Gal}$ residue is of minor importance ( $\beta 1-4$ and $\beta 1-6$ are slightly better than $\beta 1-3)$, whereas chain length and the structure of additional vicinal sugar residues are not relevant. SA on the surface of living trypomastigotes of T.cruzi is transferred back and forth between the parasite surface and acceptor molecules with terminal $\beta$-Gal, either in solution or on the surface of neighbouring mammalian cells. Addition of fucose residue on or close to the terminal galactose impairs TS activity. As a consequence, the enzyme acts poorly on the E-selectin ligand sialyl-Lewis ${ }^{x}$ and its precursor Lewis ${ }^{x}$, and in vitro adhesion of TS-treated neutrophils to L-cells expressing L-selectin is not affected. Modifications in the structure of the ( $\alpha 2-3)$-linked $N$-acetyl-neuraminic acid (Neu5Ac) (deoxy or methoxy) of the donor molecules do not impair transfer if the changes are at $C_{9}$, whereas changes at $C_{4}, C_{7}$ and $C_{8}$ impair the ability to donate the modified SA. Compounds with modified $\mathrm{C}_{4}$ and $\mathrm{C}_{8}$ inhibit $\mathrm{TS}$ at relatively high inhibitor/substrate ratios.

Key words: selectins/sialic acid/sialidase/trans-sialidase/ Trypanosoma cruzi

\section{Introduction}

Trypanosoma cruzi is the flagellated protozoan parasite that causes Chagas' disease, an incurable multisystemic disorder affecting millions of individuals in Latin America (GarciaZapata et al., 1991). In the mammalian host, the amastigote forms of the parasite multiply in the cytoplasm of cells. After several cycles of replication, the amastigotes transform into flagellated trypomastigotes, which rupture the host cells and enter the circulation. The cycle is sustained when the trypomastigotes invade new cells. The attachment (Schenkman et al., 1991b) and invasion (Schenkman et al., 1992a) of mammalian cells by the trypomastigotes involves a surface membrane sialic acid (SA)-containing, stage-specific epitope (Ssp-3) (Andrews et al., 1987). The sialylated form of Ssp-3 reacts with a panel of monoclonal antibodies (mAb) (Andrews et al., 1987; Schenkman et al., 1991b, 1992a), but removal of SA hinders recognition by the mAbs (Schenkman et al., 1991a).

Trypanosoma cruzi does not synthesize SA (Schauer et al., 1983), but acquires it from host glycoconjugates (Previato et al., 1985; Zingales et al., 1987) by means of a membrane trans-sialidase (TS) (Schenkman et al., 1991a; Parodi et al., 1992). This enzyme differs from all other known sialyl- and glycosyl-transferases in that it does not require a nucleotidesugar as donor. Here we study the substrate specificity of the T.cruzi TS using biochemical and immunological approaches. In addition, we investigate the possibility that the enzyme may influence the migrating patterns of leukocytes by modifying the E-selectin ligands, sialyl-Lewis ${ }^{\mathbf{x}}$ and sialyl-Lewis ${ }^{\mathrm{a}}$ (Tyrrell et al., 1991; Foxall et al., 1992).

\section{Results}

\section{SA acceptors}

We initially examined the structural requirements for saccharides and glycolipids to accept SA in the reaction catalysed by TS. We assayed for the ability of these compounds to decrease the amounts of radiolabelled sialyllactose formed in a reaction mixture containing TS, $3^{\prime}$-sialyllactose as a donor of SA and $\left[{ }^{14} \mathrm{C}\right]$ lactose as the acceptor. As shown in Table IA, transfer of $S A$ to radiolabelled lactose decreases in the presence of disaccharides containing $\beta$-linked, but not $\alpha$-linked terminal galactopyranosyl residues. Glc, GlcN, GaiN, Fuc, GlcNac, GalNac, Man, and disaccharides containing GalNAc, Glc, GlcNAc and Man at the non-reducing end, are inactive. Gal is a poor acceptor (Table IC), but TS efficiently transfers SA to methyl- $\beta$-Gal, but not to methyl- $\alpha-\mathrm{Gal}$, confirming its specificity towards $\beta$-linked galactopyranosyl residues. Nevertheless, oligosaccharides containing non-terminal $\beta$-Gal residues are not good acceptors (see Table IB, $2^{\prime}$-FL and LNFP-I).

The reducing end of disaccharides influences the reaction since $\operatorname{Gal}(\beta 1-4) \mathrm{GlcNAc}$ and $\operatorname{Gal}(\beta 1-6) \mathrm{GlcNAc}$ are slightly better acceptors than $\operatorname{Gal}(\beta 1-3)$ GlcNAc (Table IA and B). Chain length does not alter reactivity [compare LNnt with $\mathrm{Gal}(\beta 1-4) \mathrm{GlcNAc}$, and LNT versus $\mathrm{Gal}(\beta 1-3) \mathrm{GlcNAc}$, in Tables IA and B]. Addition of a fucose residue, however, significantly diminishes the capacity to inhibit formation of $\left[{ }^{14} \mathrm{C}\right] 3^{\prime}$-sialyllactose. The effect of the fucose residue decreases as it is positioned further away from the terminal Gal. While reactivity is almost totally blocked if the fucose residue is linked directly to the terminal Gal (see 2'-FL, LNFP-I, Table IB), the presence of branched fucose residues further away (compare LNFP-II and LNFP-V) is less inhibitory. Lewis ${ }^{x}$ (LNFP-III) is a poor acceptor (see Table IB).

We performed additional experiments using as a donor $4^{\prime}$ methyl-umbelliferyl $\mathrm{N}$-acetyl-neuraminic acid (MU-Neu5Ac). 
Table I. Ability of various compounds to decrease the TS-mediated formation of [sialyl- ${ }^{14} \mathrm{C}$ ]lactose. Results are expressed as percent reduction in the synthesis of [sialyl- ${ }^{14} \mathrm{C}$ ] lactose in a reaction mixture containing TS, $1 \mathrm{mM}$ sialyllactose and $25000-40000 \mathrm{c} . \mathrm{p} . \mathrm{m}$. [D-glucose-1 $-{ }^{14} \mathrm{C}$ ]lactose by adding different concentrations of potential acceptor molecules

(A) Disaccharides and derivatives

\begin{tabular}{|c|c|c|c|c|}
\hline \multirow[t]{2}{*}{ Saccharides } & \multirow[t]{2}{*}{ Name } & \multicolumn{3}{|c|}{ Concentration $(\mu \mathrm{M})^{\circ}$} \\
\hline & & 100 & 1000 & 10000 \\
\hline $\mathrm{Gal}(\beta 1-4) \mathrm{Glc}$ & Lactose & 26 & 76 & 86 \\
\hline Gal $(\dot{\beta 1}-4)$ fructose & Lactulose & - & 59 & 78 \\
\hline Gal $(\beta 1-4)$ gluconic acid & Lactobionic acid & 26 & 50 & 74 \\
\hline Gal $(\beta 1-4)$ GlcNAc & $\mathrm{N}$-Acetyl-lactosamine & 36 & 76 & 89 \\
\hline $\operatorname{Gal}(\beta 1-4)$ Man & & - & 36 & 71 \\
\hline $\mathrm{Gal}(\beta 1-4) \mathrm{Glc}-\mathrm{O}-\mathrm{CH}_{3}$ & & 42 & 61 & 77 \\
\hline $\mathrm{Gal}(\beta 1-3) \mathrm{GlcNAc}$ & & - & - & 52 \\
\hline $\operatorname{Gal}(\beta 1-3) \mathrm{GalNAC}$ & & 5 & 28 & 55 \\
\hline $\operatorname{Gal}(\beta 1-3)$ arabinose & & 7 & 37 & 66 \\
\hline $\mathrm{Gal}(\beta 1-3) \mathrm{Gal}-\mathrm{O}-\mathrm{CH}_{3}$ & & 18 & 67 & 78 \\
\hline $\mathrm{Gal}(\beta 1-6) \mathrm{Gal}$ & & - & 38 & 83 \\
\hline $\mathrm{Gal}(\beta 1-6) \mathrm{GlcNAc}$ & & - & 40 & 89 \\
\hline $\mathrm{Gal}(\alpha \mathrm{l}-4) \mathrm{Gal}$ & & - & - & - \\
\hline $\mathrm{Gal}(\alpha 1-3) \mathrm{Gal}-\mathrm{O}-\mathrm{CH}_{3}$ & & 6 & 4 & 13 \\
\hline $\operatorname{Gal}(\alpha 1-6) \mathrm{Glc}$ & Melibiose & - & - & - \\
\hline $\mathrm{Gal}(\alpha 1-6) \mathrm{Gal}$ & Stachyose & - & - & - \\
\hline $\mathrm{GalNAc}(\beta 1-3) \mathrm{Gal}-\mathrm{O}-\mathrm{CH}_{3}$ & & - & 1 & - \\
\hline $\operatorname{Glc}(\beta 1-4) \mathrm{Glc}$ & Cellobıse & - & - & - \\
\hline $\operatorname{Glc}(\alpha 1-6)$ fructose & Palatınose & - & - & - \\
\hline $\operatorname{Glc}(\alpha 1-4) \mathrm{Glc}$ & Maltose & - & - & - \\
\hline Glc $(\alpha 1-1 \beta)$ fructose & Sucrose & - & - & - \\
\hline $\operatorname{Glc}(\alpha 1-1 \alpha)$ Glc & $\alpha, \alpha$-Trehalose & - & - & - \\
\hline $\operatorname{GlcNAc}(\beta 1-3)$ Gal-O- $\mathrm{CH}_{3}$ & & - & - & - \\
\hline $\operatorname{GlcNAc}(\beta \mid-6) \mathrm{Gal}$ & & - & - & - \\
\hline $\operatorname{GlcNAc}(\beta 1-4) \operatorname{GlcNAc}$ & Chitobiose & - & - & - \\
\hline $\operatorname{GlcNAc}(\beta 1-6) \operatorname{GlcNAc}$ & & - & - & 1 \\
\hline $\operatorname{GlcNAc}(\beta 1-6) \mathrm{Man}-\mathrm{O}-\mathrm{CH}_{3}$ & & - & - & 4 \\
\hline $\operatorname{Man}(\alpha 1-3) \operatorname{Man}$ & & - & - & - \\
\hline
\end{tabular}

- - no reduction.

(B) Oligosaccharides

\begin{tabular}{|c|c|c|c|c|}
\hline \multirow[t]{2}{*}{ Name } & \multirow[t]{2}{*}{ Saccharides } & \multicolumn{3}{|c|}{ Concentration $(\mu \mathrm{M})$} \\
\hline & & 100 & 1000 & 10000 \\
\hline LNnT & $\operatorname{Gal}(\beta 1-4) \operatorname{GlcNAc}(\beta 1-3) \operatorname{Gal}(\beta 1-4) \mathrm{Glc}$ & 12 & 69 & 84 \\
\hline LNT & $\operatorname{Gal}(\beta 1-3) \mathrm{GlcNAc}(\beta 1-3) \mathrm{Gal}(\beta 1-4) \mathrm{Glc}$ & 1 & 13 & 69 \\
\hline $2^{\prime}-\mathrm{FL}$ & $\operatorname{Fuc}(\alpha 1-2) \mathrm{Gal}(\beta 1-4) \mathrm{Glc}$ & 6 & - & 12 \\
\hline 3-FL & $\operatorname{Gal}(\beta 1-4)[\operatorname{Fuc}(\alpha 1-3)] \mathrm{Glc}$ & - & 11 & 61 \\
\hline LNFP-I & $\operatorname{Fuc}(\alpha 1-4) \mathrm{Gal}(\beta 1-3) \operatorname{GlcNAc}(\beta 1-3) \mathrm{Gal}(\beta 1-4) \mathrm{Glc}$ & - & 8 & 28 \\
\hline LNFP-II & $\operatorname{Gal}(\beta 1-3)[\operatorname{Fuc}(\alpha 1-4)] \operatorname{GlcNAc}(\beta 1-3) \mathrm{Gal}(\beta 1-4) \mathrm{Glc}$ & - & 12 & 21 \\
\hline LNFP-IIP & $\operatorname{Gal}(\beta 1-4)[\operatorname{Fuc}(\alpha 1-3)] \operatorname{GlcNAc}(\beta 1-3) \operatorname{Gal}(\beta 1-4) \mathrm{Glc}$ & - & 18 & ND \\
\hline LNFP-V & $\mathrm{Gal}(\beta 1-3) \mathrm{GlcNAc}(\beta 1-3) \mathrm{Gal}(\beta 1-4)[\mathrm{Fuc}(\alpha 1-3)] \mathrm{Glc}$ & 9 & - & 52 \\
\hline
\end{tabular}

"Lewis".

(C) Monosaccharides and derivalives

\begin{tabular}{llcc}
\hline Name & Concentration $(\mu \mathrm{M})$ & & \\
\cline { 2 - 4 } & 100 & 7000 & 10000 \\
\hline Galactose & - & 19 & 20 \\
$\alpha$-Methyl-galactose & 13 & 37 & 17 \\
$\beta$-Methyl-galactose & 26 & 81 \\
\hline
\end{tabular}

¿Glucose (Glc), glucosamine (GlcN), galactosamine (GalN), fucose (Fuc), N-aceryl-glucosamıne (GlcNAc), N-acetyl-galactosamıne (GalNAc) and mannose (Man) were all tested and found to be negative. 
All $\beta$-linked galactosides are sialylated by TS in the presence of MU-Neu5Ac (Figure 1, lanes C, D and E), whereas $\operatorname{Gal}(\beta 1-4)[\mathrm{Fuc}(\alpha 1-3)] \mathrm{Glc}\left(3^{\prime}-\mathrm{FL}\right.$, lane B) is only poorly sialylated. Note that in the absence of SA acceptors (lane F), or in the presence of saccharides which are not good acceptors (lane B), free SA is generated. This confirms that under these conditions the enzyme acts more as a neuraminidase [better called sialidase (Reuter and Schauer, 1988)] than as a trans-sialidase (Schenkman et al., 1992b).

\section{SA donors}

Next, we assayed for the ability of various sialylated molecules to act as donors of SA to $\left[{ }^{14} \mathrm{C}\right]$ lactose. As shown in Table II, ( $\alpha 2-3)$-linked, but not $(\alpha 2-6)$ - or ( $\alpha 2-9)$-linked SA is transferred to $\left[{ }^{14} \mathrm{C}\right]$ lactose. In parallel with the results above (Table I), the saccharides in which $\mathrm{Gal}$ is $(\beta 1-4)$ linked are better SA donors than those in which Gal is $(\beta 1-3)$ linked (compare GSC-31 and GSC-30, Table IIA). The presence of fucose linked to the terminal Gal hampers donation of SA (compare $3^{\prime}$-sialyllactose with $3^{\prime}-\mathrm{S}, 3-\mathrm{FL}$, Table IIB), but if the fucose is attached to the penultimate residue, there is some transfer (as in sialyl-Lewis ${ }^{x}$, Table IIA). Table IIC shows that transfer only occurs if SA is $(\alpha 2-3)$ linked to terminal and not internal galactopyranosyl residues. Table IIB further demonstrates that any sialylated terminal $\beta-\mathrm{Gal}$, whether $\mathrm{O}$ - or $\mathrm{N}$-linked type oligosaccharides, are potential donors.

\section{TS inhibitors}

In Table IID we studied the effect of structural changes in the neuraminic acid residue of $\mathrm{GM}_{3}$-gangliosides which, as expected, are good SA donors. Modifications at $\mathrm{C}_{9}$ (deoxy or methoxy) do not alter the ability of the gangliosides to donate $\mathrm{SA}$, whereas changes at $\mathrm{C}_{4}$ (deoxy or methoxy), $\mathrm{C}_{7}$ (deoxy) and $\mathrm{C}_{8}$ (deoxy or epi) are profoundly inhibitory. In addition, Table III shows that some of these compounds are in fact inhibitors of TS activity. GSC-77, GSC-75 and GSC-50 (but not the other gangliosides) partially prevent the transfer of SA from $3^{\prime}$-sialyllactose to $\left[{ }^{14} \mathrm{C}\right]$ lactose at $1 / 10$ inhibitor/substrate ratios.

The inhibitory activity of the compounds was also shown in vivo. At relatively high concentrations GSC-84, the saccharide portion of GSC-77, partially inhibits sialylation of trypomastigotes grown in bovine serum albumin (BSA) when incubated with $3^{\prime}$-sialyllactose (Table IV). GSC-84 was used instead of GSC-77 because the ceramide portion of GSC-77 caused aggregation of the trypomastigotes (data not shown). Nevertheless, complete inhibition of TS was not achieved with any of the gangliosides, thus rendering them of little use for biological experiments. Table III also shows that 2,3-dehydro2-deoxy-Neu5Ac, a potent inhibitor of bacterial and viral sialidases (Meindl et al., 1974), has little or no effect on TS activity.

\section{Ssp-3 is a donor of $S A$}

Previous studies demonstrated that the Ssp-3 epitope of trypomastigotes (Andrews et al., 1987) is assembled through the TS-catalysed transfer of $(\alpha 2-3)$-linked SA from host macromolecules to parasite surface molecules (Schenkman et al., 1991a). To determine whether this reaction is reversible, and whether Ssp-3 can in turn donate SA to other cells, we mixed parasites grown in Dulbecco's modified Eagle's medium (DMEM)-BSA with parasites grown in DMEM-fetal bovine

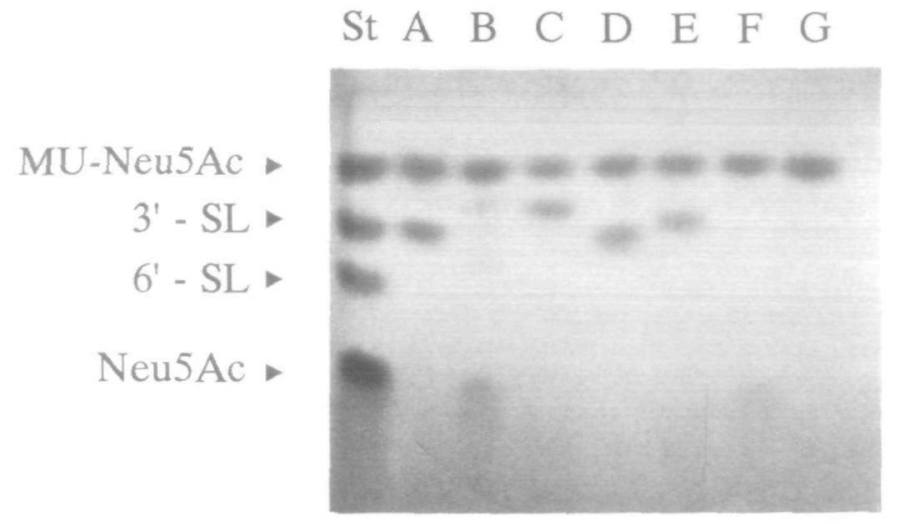

Fig. 1. Saccharides with terminal $\beta$-linked Gal are acceptors for TS. Affinity purified TS was incubated for $3 \mathrm{~h}$ at room temperature with MU-Neu5AC and different oligosaccharides (lane A: lactose; $\mathbf{B}$ : 3-FL; C: Gal $(\beta 1-3)$ GlcNAc; D: Gal $(\beta 1-6) \mathrm{GlcNAc} ; \mathbf{E}: \mathrm{Gal}(\beta 1-3) \mathrm{GalNAc})$ as indicated. In the control reaction mixtures, TS (lane F) or heat-inactivated TS (lane G) was incubated with MU-Neu5Ac alone. The reactions were stopped by adding ethanol and the products were analysed by TLC on silica gel 60 plates in ethanol- $n$-butanol-pyridine-water-acetic acid

[100:10:10:30:3 (v/v)]. SA-containing molecules were visualized by resorcinol staining. MU-Neu5Ac, 3'-sialyllactose, 6 '-sialyllactose and Neu5Ac were used as standards (arrows).

serum (FBS) and incubated the mixture for $60 \mathrm{~min}$ at $37^{\circ} \mathrm{C}$. The mixture was then subjected to FACS analysis using mAb $3 \mathrm{C} 9$ as a revealing reagent. The reactivity of this $\mathrm{mAb}$ with Ssp-3 is dependent on the presence of SA in the epitope. As shown in Figure 2, parasites grown in DMEM-BSA (therefore in the absence of SA donors) (A) are less intensely stained (mean fluorescence $=242$ ) than those grown in medium containing FBS (B) (mean fluorescence $=1371$ ). After they are incubated together, the parasites have intermediate staining intensity $(C)$ (mean fluorescence $=1090$ ).

That Ssp-3 can act as a donor of SA was further demonstrated by incubating parasites grown in DMEM-FBS in medium containing $1 \mathrm{mM}$ of various oligosaccharides. The Ssp-3 epitope is lost if the medium contains saccharides with terminal $\beta$-Gal residues, such as lactose and $\beta$-methyl-Gal, but not if it contains saccharides with $\alpha$-terminal Gal residues, such as melibiose or $\alpha$-methyl-Gal (see Table V).

\section{Lack of TS effect on E-selectin ligand}

Sialic acid plays an important role in the selectin-mediated cell adhesion (Tyrrell et al., 1991; Foxall et al., 1992). Additional experiments were performed to examine the effect of TS on the interaction between selectins and their ligands, sialyl-Lewis ${ }^{\mathrm{a}}$ and sialyl-Lewis ${ }^{x}$. Neutrophils were treated with TS in the presence of lactose (as a SA acceptor), or with Vibrio cholerae sialidase (as a positive control). The neutrophils were then assayed for their ability to attach to L-cells transfected with E-selectin. Treatment with sialidase, but not with TS, abrogated the binding (Figure 3).

In order to document the activity of TS on SA-containing molecules from the neutrophil plasma membrane, we performed a series of control experiments. Neutrophils were preincubated with phosphate-buffered saline (PBS), with sialidase, or with TS in the presence of lactose. The cells were washed and reincubated with TS in the presence of [D-glucose-1-14 C]lactose. Negative controls consisted of cells incubated with the labelled acceptor, but in the absence of TS. As shown in Table VI, labelled sialyllactose is formed in the incubation mixtures containing neutrophils which had been pre-treated with PBS, 
Table II. Abılity of various compounds to be sialıc acid donors. [Sialyl- ${ }^{14} \mathrm{C}$ ]lactose formation in a reaction mixture containing TS, [D-glucose-1- $-{ }^{14} \mathrm{C}$ ]lactose and different concentrations of potential donor molecules was expressed as a percentage of c.p.m.s obtained in the presence of $1 \mathrm{mM}$ of a reference donor (different for every table)

(A) Gangliosides

\begin{tabular}{|c|c|c|c|c|}
\hline \multirow[t]{2}{*}{ Name } & \multirow[t]{2}{*}{ Termınal saccharides } & \multicolumn{3}{|c|}{ Concentration $(\mu \mathrm{M})^{2}$} \\
\hline & & 10 & 100 & 1000 \\
\hline GSC-31 & $\operatorname{New} 5 \mathrm{Ac}(\alpha 2-3) \mathrm{Gal}(\beta 1-4) \mathrm{GlcNAc}(\beta 1-3) \mathrm{Gal}(\beta \mid-4) \mathrm{Glc} \mathrm{R}^{\mathrm{b}}$ & 71 & 91 & 100 \\
\hline GSC-64 & $\operatorname{Neu} 5 A c(\alpha 2-3) \operatorname{Gal}(\beta 1-4)[\operatorname{Fuc}(\alpha 1-3)] \operatorname{GlcNAc}(\beta 1-3) \operatorname{Glc}(\beta 1-4)$ Gal-R, stalyl-Lew1s" & 12 & 19 & 42 \\
\hline GSC-6! & Neu5Ac $(\alpha 2-6)$ Gal $(\beta 1-4)$ Glc-R & - & 18 & 10 \\
\hline GSC-65 & NeuSAc( $(\alpha 2-6) \mathrm{Gal}(\beta 1-3) \mathrm{GlcNAc}(\beta 1-3) \mathrm{Gal}(\beta 1-4) \mathrm{Glc}-\mathrm{R}$ & 3 & 9 & 1 \\
\hline
\end{tabular}

${ }^{a}$ Results are expressed as a percentage of c.p $\mathrm{m}$. formed in the presence of $1 \mathrm{mM} \mathrm{GSC}-31$.

${ }^{\mathrm{h}} \mathrm{R}=-\mathrm{O}-\mathrm{CH}_{2}-\mathrm{CH}\left(\mathrm{NH}-\mathrm{CO}-\mathrm{CO}_{17} \mathrm{H}_{33}\right)-\mathrm{CHOH}-\mathrm{CH}=\mathrm{CHIC}_{13} \mathrm{H}_{27}$

(B) Oligosaccharides

\begin{tabular}{|c|c|c|c|c|c|}
\hline Name & Terminal sacchandes & \multicolumn{4}{|c|}{ Concentration $(\mu \mathrm{M})^{\mathrm{a}}$} \\
\hline $3^{\prime}-\mathrm{SL}$ & $\operatorname{Neu} 5 A c(\alpha 2-3) G a l(\beta 1-4) G i c$ & 36 & 63 & 100 & \\
\hline LST-a & Neu5Ac( $(\alpha 2-3) \mathrm{Gal}(\beta 1-3) \mathrm{GlcNAc}(\beta 1-3) \mathrm{Gal}(\beta 1-4) \mathrm{Glc}$ & 0 & 2 & 31 & 71 \\
\hline 3'-S,3-FL & $\operatorname{Neu} 5 \operatorname{Ac}(\alpha 2-3) \operatorname{Gal}(\beta 1-4)[\operatorname{Fuc}(\alpha 1-3)] \mathrm{Glc}$ & 3 & 2 & 8 & \\
\hline$C-446300$ & $\mathrm{~N}$-linked type oligosacchande & 53 & 89 & & \\
\hline
\end{tabular}

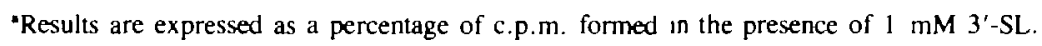

(C) Gangliosides with terminal and non-terminal SA

\begin{tabular}{|c|c|c|c|c|}
\hline \multirow[t]{2}{*}{ Name } & \multirow[t]{2}{*}{ Terminal saccharides } & \multicolumn{3}{|c|}{ Concentration $(\mu \mathrm{M})^{\wedge}$} \\
\hline & & 10 & 100 & 1000 \\
\hline Monosialo-GM, & $\mathrm{Gal}(\beta 1-3) \mathrm{GalNAc}(\beta 1-4)[\operatorname{Neu} 5 \mathrm{Ac}(\alpha 2-3)] \mathrm{Gal}(\beta 1-4) \mathrm{Glc}-\mathrm{Cer}$ & 5 & 6 & 6 \\
\hline Monosialo- $\mathrm{GM}_{3}$ & $\operatorname{NeuSAc}(\alpha 2-3) \mathrm{Gal}(\beta 1-4) \mathrm{Glc}-\mathrm{Cer}$ & 52 & 122 & 100 \\
\hline
\end{tabular}

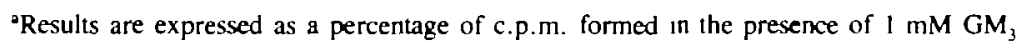

(D) $\mathrm{GM}_{3}$-ganglıosides [Neu5Ac( $\left.\alpha 2-3\right) \mathrm{Gal}(\beta 1-4) \mathrm{Glc}-\mathrm{R}$ ] with varnations in the Neu5Ac residue

\begin{tabular}{|c|c|c|c|c|}
\hline \multirow[t]{2}{*}{ Name } & \multirow[t]{2}{*}{ Variations in Neu5Ac } & \multicolumn{3}{|c|}{ Concentration $(\mu \mathrm{M})^{\kappa}$} \\
\hline & & 10 & 100 & 1000 \\
\hline GSC-17 & NeuSAc & 18 & 86 & 100 \\
\hline GSC-51 & 9-deoxy Neu5Ac & 32 & 88 & 107 \\
\hline GSC-75 & 4-deoxy NeuSAc & 1 & 5 & 9 \\
\hline GSC-76 & 7-deoxy NeuSAc & 0 & 1 & 4 \\
\hline GSC-79 & 9-methoxy NeuSAc & 24 & 71 & 71 \\
\hline
\end{tabular}

${ }^{a}$ Results are expressed as a percentage of c.p.m. formed in the presence of $1 \mathrm{mM} \mathrm{GSC}-17\left(\mathrm{GM}_{3}\right)$.

but not with sialidase, or with TS in the presence of lactose. We conclude that TS removes $(\alpha 2-3)$-linked SA from the plasma membrane of the neutrophils. However, the E-selectin ligands, sialyl-Lewis ${ }^{x}$ and sialyl-Lewis ${ }^{a}$, that contain branched fucose, are less (or not) affected.

\section{Discussion}

Glycosyl transfer reactions are common in nature, the most common type being the transfer of a glycosyl unit from a sugar nucleotide to an acceptor. Transglycosylation in the absence of nucleotide-sugars is unusual because this process is thermodynamically unfavourable (Cote and Tao, 1990). Nevertheless, many enzymes that primarily catalyse the hydrolysis of oligosaccharides can perform transglycosylation reactions, albeit much less efficiently. The hydrolysis of the glycosidic bond by these enzymes is simply a special case of transglycosylation, in which the acceptor is water. This is also the case for the T.cruzi TS, whose sialidase activity (Pereira, 1983) was detected prior to its trans-sialidase activity (Schenkman et al., 
Table III. Inhibition of transfer of SA by 2,3-dehydro-2-deoxy-Neu5Ac and

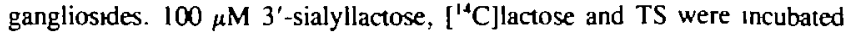
with sialyl-sacchandes at different concentrations for $3 \mathrm{~min}$ at room temperature. Inhibition is expressed as pencentage reduction of c.p.m. obtained in the absence of the sialyl-sacchandes

\begin{tabular}{lcccc}
\hline SA-saccharide & \multicolumn{4}{c}{ Concentration $(\mu \mathrm{M})^{\mathbf{b}}$} \\
\cline { 2 - 5 } & 1 & 10 & 100 & 1000 \\
\hline 2,3-dehydro-2-deoxy-Neu5AC & 3 & - & - & 9 \\
GSC-77 & - & 44 & 79 & 90 \\
GSC-75 & - & 46 & 87 & 80 \\
GSC-50 & 12 & 24 & 60 & 84 \\
GSC-76 & - & - & - & 52 \\
GSC-96 & - & - & - & 9 \\
GSC-61 & - & - & - & 25 \\
\hline
\end{tabular}

The substances tested do not transfer sialic acid to $\left[{ }^{14} \mathrm{C}\right]$ lactose (see Table ID)

$b_{-}$, no inhibition.

Table IV. Inhibition of sialylation of trypomastigotes by GSC-84 Trypomastigotes were grown in DMEM-BSA and incubated with $3^{\prime}$-sialyllactose $(0.01 \mathrm{mM})$ or $3^{\prime}$-sialyllactose + GSC-84 $(01 \mathrm{mM})$ for 5 or $30 \mathrm{~min}$ at $37^{\circ} \mathrm{C}$, stained with an antibody recognizing a stalylated epitope (mAb 3C9) and subjected to FACS analysis

\begin{tabular}{llc}
\hline Trypomastigotes incubated with & \multicolumn{2}{c}{ Mean fluorescence after } \\
\cline { 2 - 3 } & $5 \mathrm{~min}$ & $30 \mathrm{~mm}$ \\
\hline DMEM - BSA & 234 & 180 \\
DMEM - BSA + SL & 983 & 1377 \\
DMEM - BSA + SL + GSC-84 & 674 & 695 \\
\hline
\end{tabular}

1991a). However, the T.cruzi enzyme is exceptional in that it is more efficient in transferring than in hydrolysing SA (Parodi et al., 1992; Schenkman et al., 1992b). Also, in contrast with the glycosyltransferases, it does not use CMP-SA (which contains $\beta$-linked SA) as a donor of SA (Corfield and Schauer, 1982).

In this paper, we characterize the substrate specificity of the T.cruzi TS using biochemical and immunological approaches. We show that saccharides with terminal $\beta$-Gal (but not $\alpha-\mathrm{Gal}$ ) are acceptors, and saccharides with terminal Neu5Ac $(\alpha 2-3)$ linked to $\beta$-Gal [but not $(\alpha 2-6)$-linked], are donors of SA (Tables I and II). The presence of a residue in $\beta$-linkage to $\mathrm{Gal}$ is necessary for catalysis; $\mathrm{Gal}$ is not an acceptor, although in aqueous solutions $\mathrm{Gal}$ occurs mostly as a $\beta$-anomer (El Khadem, 1988). On the other hand, a single linked carbon atom (methyl- $\beta$-Gal) is sufficient to obtain reactivity (Table I). TS also transfers SA from MU-Neu5Ac, but methyl-umbelliferone is not an acceptor (Schenkman et al., 1992b). A possible interpretation of these findings is that during catalysis a sialylated enzyme intermediate is formed and the desialylated product of the reaction is released from the pocket. The enzyme-bound $\mathrm{SA}$ is then transferred to any available $\beta$-Galcontaining structure, provided it can be accommodated in the enzyme pocket. Although chain length and the structure of additional vicinal sugar residues seem irrelevant, addition of a fucosyl side chain to the terminal $\beta-\mathrm{Gal}$ inhibits transfer, most likely because it prevents entrance of the saccharide in the active site of TS (Tables I and II), as in the case of mammalian sialyl-transferases (Paulson et al., 1978).
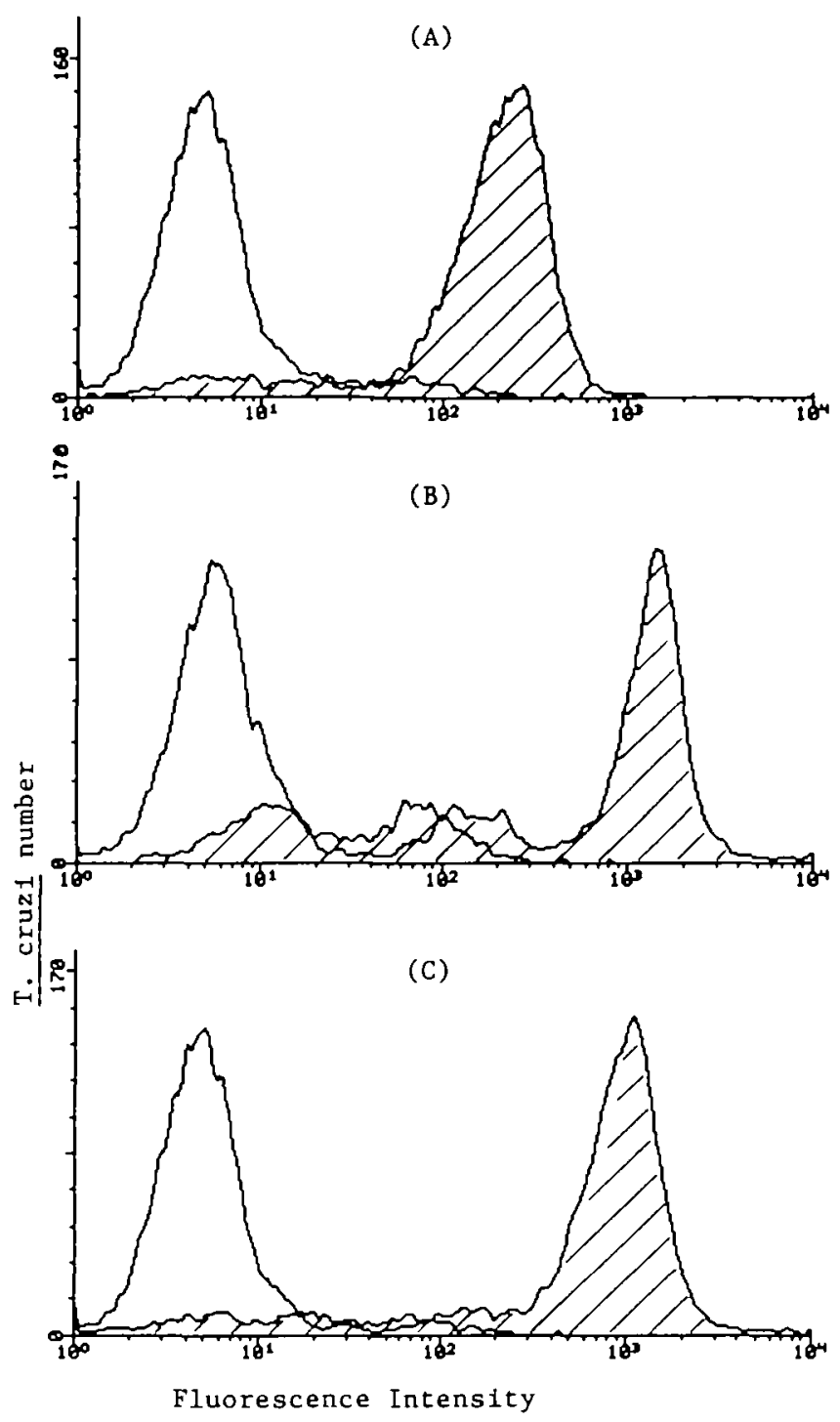

Fig. 2. The acquistion of SA by trypomastigotes is reversible. Parasites were washed in DMEM-BSA and divided into two aliquots. One was incubated with the mAb 3C9 against the Ssp-3 epitope. Parasites were then stained with goat anti-mouse IgG-FITC and analysed by FACS. Three different samples of trypomastigotes were analysed, originating from cultures in DMEM-BSA (A), cultures in DMEM-FBS (B), or a mixture of equal numbers of (A) and (B) which was pre-ıncubated at $37^{\circ} \mathrm{C}$ for 60 min pror to staining (C). Unshaded curves represent the background obtained by staining with the secondary antibody only; shaded curves represent the 3C9-stained samples.

Table V. Ssp-3 is a donor of sualic acid. Trypomastigotes were grown in medium contanning BSA or FCS as described. Parasites were then incubated with different saccharides $(1 \mathrm{mM})$ for $1 \mathrm{~h}$ at $37^{\circ} \mathrm{C}$, stained with the $3 \mathrm{C} 9$ antibody and analysed by FACS

\begin{tabular}{llc}
\hline $\begin{array}{l}\text { Trypomastigotes } \\
\text { grown in }\end{array}$ & $\begin{array}{l}\text { Additional } \\
\text { incubation in }\end{array}$ & $\begin{array}{l}\text { Mean } \\
\text { fluorescence }\end{array}$ \\
\hline BSA & PBS & 234 \\
FCS & PBS & 1905 \\
& Lactose & 746 \\
& Melibiose & 1649 \\
& $\beta G a l-O-\mathrm{CH}_{3}$ & 848 \\
& $\alpha G a l-O-\mathrm{CH}_{3}$ & 1845 \\
\hline
\end{tabular}




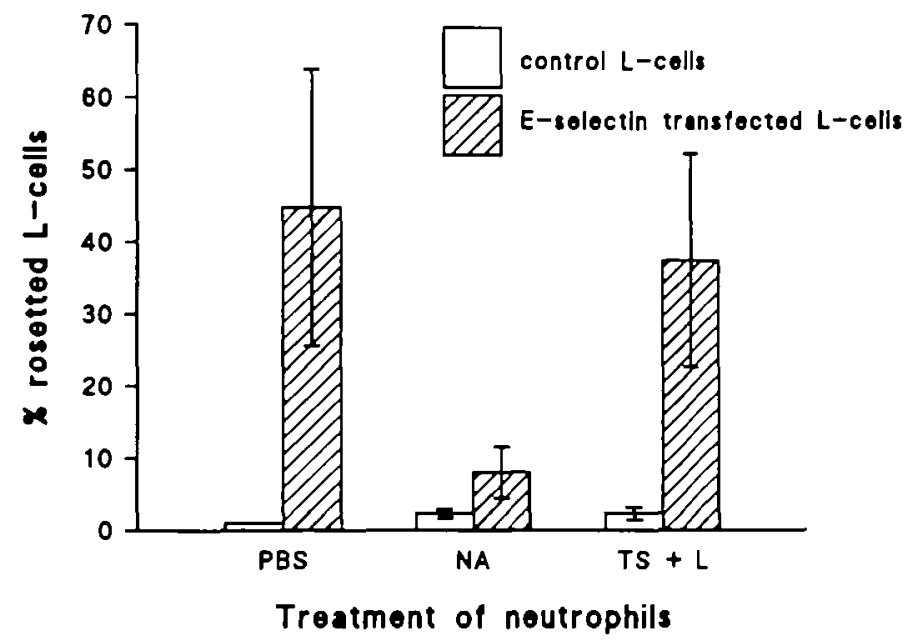

Fig. 3. TS does not affect the binding of neutrophils to L-cells transfected with E-selectin. Polymorphonuclear leukocytes were washed three tumes with DMEM and resuspended in DMEM-Pipes ( $50 \mathrm{mM}, \mathrm{pH} 6.5)$. Cells $\left(8 \times 10^{6}\right)$ were treated with $0.2 \mathrm{U} / \mathrm{ml} \mathrm{V}$.cholerae siahdase, with punfied TS in the presence of $1 \mathrm{mM}$ lactose, or with an equal volume of PBS. Neutrophils were incubated at $37^{\circ} \mathrm{C}$ for $90 \mathrm{~min}$, spun down and washed twice with DMEM. Cultures of L-cells transfected with E-selectin cDNA were washed once with DMEM without FBS, and co-incubated with $2 \mathrm{ml}$ of the neutrophil suspension at $37^{\circ} \mathrm{C}$ on a rotary shaker. The medium was removed after $60 \mathrm{~min}$ and the cells washed six times with DMEM without FBS. Rosetting of neutrophils around the adherent L-cells was evaluated microscopically and expressed as percentage of L-cells with more than one neutrophil attached.

Tabłe VI. TS-mediated transfer of sialic acid from neutrophils Neutrophils $\left(7 \times 10^{6}\right.$ cells) were pre-treated with PBS, with sialidase or with TS + lactose, and then incubated in DMEM-Hepes $(50 \mathrm{mM}, \mathrm{pH} 7.2)$ with TS and [D-glucose-1-14 C]lactose for $90 \mathrm{~min}$ at room temperature on a rotary shaker. The supernatants were then passed over a QAE column and radioactivity measured as described in Materials and methods

\begin{tabular}{lc}
\hline $\begin{array}{l}\text { Neutrophils } \\
\text { pre-treated with }\end{array}$ & $\begin{array}{c}\text { c.p.m. retained on } \\
\text { the QAE column }\end{array}$ \\
\hline PBS & 945 \\
TS + L & 58 \\
Sialidase & 80 \\
PBS" & 125 \\
\hline
\end{tabular}

Neutrophils were incubated with [D-glucose-1 $\left.-{ }^{14} \mathrm{C}\right]$ lactose in the absence of TS.

As shown in Table III, the compounds with modified $\mathrm{C}_{4}$ and $\mathrm{C}_{8}$ (deoxy) in the ( $\alpha 2-3$ )-linked Neu5Ac are inhibitors of TS, suggesting that these are sites for SA recognition/catalysis. This is in contrast with the saccharides bearing ( $\alpha 2-6)$ - or ( $\alpha 2-9)$ linked SA, which are neither donors nor inhibitors and probably do not enter the enzyme pocket.

Every donor molecule tested (with the exception of MUNeu5Ac, see above) can become an acceptor after release of SA (Tables I and II). This is also valid for Ssp-3, the sialylated stage-specific epitope of T.cruzi (Andrews et al., 1987). Studies performed with live trypomastigotes show that SA can be transferred back and forth between the parasite surface and acceptor molecules (Figure 2, Tables V and VI). It is conceivable that this continuous transfer of SA might in fact be part of the molecular events occurring during parasite attachment to and invasion of host cells (Schenkman et al., 1991b).
On the basis of the initial studies on the substrate specificity of TS, it was suggested (Kahn et al., 1991; Schenkman et al., 1991a) that TS might remove the SA from the selectin ligands [sialyl-Lewis ${ }^{\mathrm{x}}$ and sialyl-Lewis ${ }^{\mathrm{a}}$ (Tyrrell et al., 1991; Foxall et al., 1992)]. If this were true, the TS shed from the parasite surface (Frevert et al., 1992b; Schenkman et al., 1992), and found in the circulation during the acute stages of the infection (de Titto and Araujo, 1988; Affranchino et al., 1989), might disrupt specific interactions between leukocytes, platelets and the vascular endothelium. However, the data in Table II, showing that fucosylated saccharides are not very good substrates for the TS, render this unlikely. The biochemical data were substantiated by direct experiments showing that in vitro adhesion of TS-treated neutrophils to L-cells expressing L-selectin was not significantly affected (Figure 3).

TS is a homopolymer with subunits of 160000-200000 $\mathbf{M}_{\mathrm{r}}$, with the amino-terminal half of the polypeptide chain containing the catalytic site (Parodi et al., 1992; Uemura et al., 1992). This region of the molecule contains consensus sequences (S-X-D-X-G-X-T-W) which are homologous to the ASP boxes in the viral and bacterial sialidases (Roggentin et al., 1989; Russo et al., 1990; Kahn et al., 1991; Pollevick et al., 1991; Uemura et al., 1992). In spite of these similarities, TS has properties distinct from the other sialidases. TS is most active at neutral $\mathrm{pH}$, whereas most sialidases are more active at acidic $\mathrm{pH}$. Competitive inhibitors of sialidases, such as 2,3-dehydro-3-deoxy-Neu5Ac, do not inhibit TS (Table III). In fact, ASP boxes are found in proteins that do not have sialidase activity, but are involved in binding to saccharides (Takle and Cross, 1991). Similarly, ASP boxes are found in trypomastigote surface molecules lacking sialidase activity (Takle and Cross, 1991; Uemura et al., 1992). Perhaps ASP boxes function in the recognition of saccharides, rather than in catalysis, and may be required to attach $T$.cruzi trypomastigotes to cells or to the extracellular matrix. The recent cloning of several members of the TS family of genes, some of which lack TS activity (Uemura et al., 1992), should facilitate the identification of domains of the polypeptide chain involved in the recognition of donors and acceptors of SA, as well as in catalysis.

\section{Materials and methods}

\section{Parasites}

Trypanasoma cruzi trypomastigotes, Y strain (Silva and Nussenzweig, 1953), were obtained from infected LLC-MK 2 cells (ATCC-CCL-7, Rockville, MD), grown in low-glucose DMEM w/th penicillin and streptomycin (Gibco, Grand Island, NY), containing $10 \%$ FBS. Subconfluent cultures of LLC- $\mathrm{MK}_{2}$ cells, kept at $37^{\circ} \mathrm{C}$ in $5 \% \mathrm{CO}_{2}$, were infectod with $5 \times 10^{6}$ trypomastigotes/ $75 \mathrm{~cm}^{2}$ flask. The parasites remaining extracellular after $24 \mathrm{~h}$ were removed and the cultures maintained in 10\% FBS-DMEM. In some expenments, the FBS-containing medium was removed during the third day following infection, the monolayers washed twice with PBS, and culture continued in DMEM containing 0.2\% BSA (ultrapure, Boehringer Mannheim, Indianapolis, IN) and $20 \mathrm{mM}$ Hepes (pH 7.4) (0.2\% BSA-DMEM). There was no difference in the numbers or morphology of parasites obtained from cultures in $0.2 \%$ BSA-DMEM (BSA-trypomastigotes) or in FBS-DMEM (FBS-trypomastigotes). On day 5 after infection, the culture supermatants containing trypomastigotes, intermediate forms and amastigotes were centrifuged at $2000 \mathrm{~g}$ for $5 \mathrm{~min}$ and incubated at $37^{\circ} \mathrm{C}$. The motile trypomastigotes were collected from the supernatant after $2 \mathrm{~h}$.

\section{Enzyme purification}

TS activity was purified as described previously (Schenkman et al., 1992b), with slight modifications. Pooled supernatants from cultures of BSA-trypomastsgotes were passed through a $0.22 \mu \mathrm{m}$ Millipore filter and then concentrated -20 times by filtration through Amicon membranes with a $300000 \mathrm{~mol}$. wt 
cutoff (XM300, Amicon Co, Lexington, MA). The supernatants were adjusted to $0.5 \mathrm{M} \mathrm{NaCl}, 1 \mathrm{mM} \mathrm{CaCl}, 1 \mathrm{mM} \mathrm{MgCl}, 1 \mathrm{mM} \mathrm{MnCl}$, and incubated with Concanavalin A-Sepharose (Pharmacia LKB Biotechnology, Uppsala, Sweden) equilibrated with $0.1 \% \mathrm{NP}-40,0.5 \mathrm{M} \mathrm{NaCl}, 50 \mathrm{mM}$ Tris-HCl (pH 7.4). The Sepharose beads were washed with $25 \mathrm{ml}$ of the equilibration buffer and the enzyme eluted by overnight incubation of the beads with $0.5 \mathrm{M}$ $\alpha$-methyl-D-mannoside in the same buffer. The eluate was then dialysed against PBS.

Alternatively, the material concentrated by passage through Amicon membrancs was incubated with mAb 39 (Schenkman et al., 1991b) immobilized on a tresyl-activated agarose column (Schleicher \& Schuell, Keene, NH), prepared according to the manufacturer's instructions. The column was washed with $0.15 \mathrm{M} \mathrm{NaCl}, 50 \mathrm{mM}$ Tris- $\mathrm{HCl}(\mathrm{pH} 7.4), 0.05 \% \mathrm{NP}-40$, and the enzyme eluted with $3.5 \mathrm{M} \mathrm{MgCl}_{2}, 20 \mathrm{mM}$ sodium phosphate (pH 6.0). The eluate was immediately filtered through a G-25 column equilibrated with $20 \mathrm{mM}$ Tris-HCl (pH 8.0).

\section{Enzyme activity measurements}

TS activity was assayed using two different procedures. (i) By incubating purified enzyme in $20 \mathrm{mM}$ Hepes buffer (Sigms H-3375) (pH 7.2) in the presence of 3 -sialyllactose and [D-glucose-1-14 C]lactose $(60 \mathrm{mCl} / \mathrm{mmol})$ (Amersham, Arlıngton Heights, IL) as described previously (Passaniti and Hart, 1988). A standard assay contained $1 \mathrm{mM} 3^{\prime}$-sialyllactose and $25000-40000$ c.p.m lactose in a final volume of $30 \mu \mathrm{l}$. This mixture was incubated for $30 \mathrm{~min}$ at $37^{\circ} \mathrm{C}$ and the reaction terminated by the addition of $1 \mathrm{ml}$ of water, followed by passage through a $1 \mathrm{ml}$ QAE-Sephadex A 50 column equilibrated in water (Phammacia LKB). The radioactive olıgosaccharides were eluted with $0.5 \mathrm{ml}$ of $1 \mathrm{M}$ ammonum formate. The effectiveness of enzyme acceptors or inhibitors was assayed by adding them at various concentrations to a standard reaction mixture. The ability of different sialylated molecules to donate their SA was evaluated by substituting them in the reaction mixture for $3^{\prime}$-sialyl lactose at various concentrations. Activity was expressed as percent reduction of control counts for the acceptor/inhibitor studies, or as percent of control counts for the donor as compared to a standard reaction run in parallel. (ii) Transfer activity was also measured by incubating affinity purified TS with $50 \mathrm{nmol}$ of MUNeuSAc and 40 nmol of the indicated oligosaccharide, in $20 \mu \mathrm{l} 5 \mathrm{mM}$ Hepes (pH 7 ) for $3 \mathrm{~h}$ at room temperature. In the control reactions, TS or heatinactivated TS were incubated with MU-Neu5Ac alone. The reactions were stopped by adding $20 \mu \mathrm{l}$ ethanol and the products analysed by TLC on slica gel 60 plates (EM Science, HPTLC Fertigplatten Kieselgel 60F254, $10 \times 10 \mathrm{~cm}$ ) and chromatographed in ethanol-n-butanol-pyridine-water-acetic acid [100:10:10:30:3 (v/v)]. SA-containing molecules were visualized by resorcinol staining. Neu5Ac, MU-Neu5Ac, 3'-sialyllactose and 6'-sialyllactose were used as standards.

\section{Saccharides, ceramides and glycoproteins}

All products were from Sigma, except those marked OG which were purchased from Oxford Glycosystem; or those marked BM, which were purchased from Boehringer Mannheim; or those synthesized at Gifu University, indicated by a reference.

Sialic acid acceptors. (i) Monosaccharides: D-Glucose, DGlc; D-Glucosamine, 2-Amino-2-deoxy-D-Glucose, DGlcN; D-Gal, DGal; D-Galactosamine, 2-Amino2-deoxy-D-Gal, DGalN; D-Mannose, D-Mannopyranose, DMan; L-Fucose, LFuc; N-Acetyl-D-Glucosamine, D-GlcNAc; N-Acetyl-D-Galactosanine, D-GalNAc; $\alpha$-Methyl-D-Galactopyranoside; $\beta$-Methyl-D-Galactopyranoside. (ii) Disaccharides: Lactose, $4-O-\beta$-D-Galactopyranosyl- $\alpha-\mathrm{D}-\mathrm{Glucose}$, DGal $(\beta 1-4) D G l c ; N$-Acetyl-Lactosamine, 2-\&cetamido-2-deoxy-4- $O$ - $\beta$-D-galactopyranosyl-D-glucopyranose, DGal $(\beta 1-4)$ DGlcNAc; 2-Acetamido-2-deoxy-6$O$ - $\beta$-D-galactopy ranosyl-D-glucopyranose, D-Gal $(\beta 1-6) D G l c N A c ; 2$-acetamido-

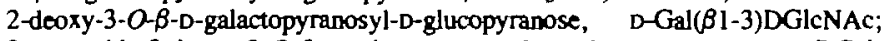
2-acetamido-2-deoxy-3- $O \beta-D$-galactopyranosyl-D-galactopyranose, DGal-

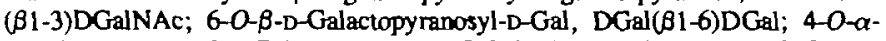
D-Galactopyranosyl-D-Galactopyranose, DGal $(\alpha 1-4) \mathrm{DGal}$; Methyl 3-O- $\alpha-\mathrm{D}-$ Galactopyranosyl- $\alpha$-D-Galactopyranoside, DGal $(\alpha 1-3) D G a l-O-C_{3}$; Methyl

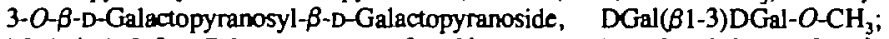
Methyl $4-O-\beta$-D-Galactopyranosyl- $\beta$-D-Glucopyranoside, DGal $(\beta 1-4) \mathrm{DGlc}-O$ $\mathrm{CH}_{3} ; 4-O-\beta$-Galactopyranosyl-D-Mannopyranose, DGal $(\beta 1-4) \mathrm{DMan} ; 3-O-\alpha-$ D-Mannopyranosyl-D-Mannopyranose, DMan( $\alpha$ 1-3)DMan; 3-O- $\beta$-D-Galactopyranosyl-D-Arabinose, DGal( $\beta$ 1-3)DAra; 2-Acetamido-6- $O$-(2-Acetamido2-deoxy- $\beta$-D-glucopyranosyl)-2-deoxy-D-glucopyranose, DGlcNAc( $\beta 1-6)$ GlcNAC; 6-O-(2-Acetamido-2-deoxy- $\beta$-D-glucopyranosyl)-D-galactopyranose, DGlcNAc $(\beta 1-6) D G a l ; M e t h y 1-3-O$ - 2-Acetamido-2-deoxy- $\beta$-D-galactopyranosyl)- $\alpha$-D-galactopyranoside, DGalNAc $(\beta 1-3)$ DGal- $\alpha-\mathrm{CH}_{3}$; Methyl-3- $O$ (2-Acetamido-2-deoxy- $\beta$-D-glucopyranosyl)- $\beta$-D-galactopyranoside, DGIcNAC$(\beta 1-3)$ DGal- $O-\mathrm{CH}_{3}$; Methyl-6-O-(2-Acetamido-2-deoxy- $\beta$-D-glucopyranosyl)-

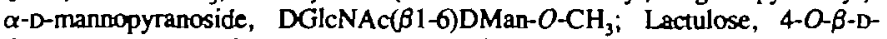
Galactopyranosyl-D-fructofuranose, DGal $(\beta 1-4) D F r$; Lactobionic Acid, 4-O$\beta$-D-Galactopyranosyl-D-gluconic acid, DGal $(\beta 1-4) D G l c N A c ;$ Palatinose, 6- $O-$
$\alpha$-D-Glucopyranosyl-D-fructofuranose, DGlu( $\alpha 1-6)$ DFru; $D-(+)$-cellobiose, 4- $-\beta$-D-glucopyranosyl-D-glucopyranosyl, DGlc $(\beta 1-4) D G l c ; D-(+)$-trehalose, $\alpha, \alpha$-Trethalose, $\alpha$-D-Glucopyranosyl- $\alpha$-D-glucopyranoside; Maltose, $4-O-\alpha-D-$ Glucopyranosyl-D-Glucose, DGlc $(\alpha 1-4)$ DGlc; Melibiose, 6-O- $\alpha$-D-Galactopyranosyl-D-Glucose, DGal( $\alpha$ 1-6)DGlc; Sucrose, $\alpha$-D-Glucopyranosyl- $\beta$-Dfructofuranoside, Glc $(\alpha 1-1 \beta)$ fructose. (iii) Oligosaccharides: 2'-Fucolactose,


DGlc $(\alpha 3-1)$ LFuc, OG; Lacto- $N$-neotetraose, LNnT, DGal $(\beta 1-4)$ DGlcNAc$(\beta 1-3) \mathrm{DGal}(\beta 1-4) \mathrm{DGlc}, \mathrm{OG}$; Lacto- $N$-tetraose, LNT, DGal $(\beta 1-3) \mathrm{DGlcNAc}-$ $\beta$ 1-3)DGal( $\beta 1-4)$ DGlc, OG; Lacto- $N$-fucopentaose I, LNFP-I, LFuc( $\alpha 1-4)$ $\operatorname{DGal}(\beta 1-3) D G l c N A c(\beta 1-3) \operatorname{DGal}(\beta 1-4) \mathrm{DGlc}, O G$; Lacto- $N$-fucopentaose II, LNFP-II, DGal $(\beta 1-3) D G l c N A c[L F u c(\alpha 1-4)](\beta 1-3) D G a l(\beta 1-4) D G l c, \quad O G$, Lacto- $N$-fucopentaose III, LNFP-II, DGal( $\beta 1-4) D G l c N A c[L F u c(\alpha 1-3)]-$ $(\beta 1-3)$ DGai $(\beta 1-4) D G l c, O G$; Stachyose, $\alpha-D-G a l-[1-6]-\alpha-D-G a]-[1-6]-\alpha-D-G] c-$ [1-2]- $\beta$-D-Fru.

Sialylared compounds. (i) Monosaccharides: 2,3-Dehydra-2-Deoxy-N-acetylneuraminic Acid, BM. (ii) Oligosaccharides: 3'-Sialyllactose, SL, N-Acetylneuraminosyl-D-Lactose, NeuSAc( $\alpha 2-3)$ DGal $(\beta 1-4) D G l c, O G ; 6 '$-Sialyllactose, SL, $N$-Acetyl-neuraminosyl-D-Lactose, Neu5Ac $(\alpha 2-6)$ DGal $(\beta 1-4) D G i c, O G$; LS-Tetrasaccharide, LST-a, Neu5Ac( $\alpha 2-3)$ DGal $(\beta 1-3)$ DGleNAc $(\beta 1-3)$ DGal$(\beta 1-4)$ DGlc, OG; 3'-Sialyl-3-fucosyllactose, 3'-S,3-FL, Neu5Ac( $\alpha 2-3)$ DGal$(\beta 1-4)$ DGlc[DFuc $(\alpha 1-3)]$, OG; tetra-sialylated, galactosylated tetra-antennary complex N-linked-type oligosacchande, containing four terminal NeuSAc$(\alpha 2-3) \mathrm{Gal}(\beta 1-4) \mathrm{GlcNAc}$ residues per molecule, OG $\mathrm{C}-446300$. (iil) Gangliosides: $\left(\mathrm{R}_{1}=-\mathrm{CH}_{2}-\mathrm{CH}\left(\mathrm{NH}-\mathrm{CO}-\mathrm{C}_{17} \mathrm{H}_{35}\right)-\mathrm{CHOH}-\mathrm{CH}=\mathrm{CH}-\mathrm{C}_{13} \mathrm{H}_{27}\right.$, $\mathrm{Cer}=$ Ceramide); Sialyl-( $\alpha 2-6)$-Lacto- $N$-tetraosylCer, $\operatorname{Neu} 5 A c(\alpha 2-6) \operatorname{DGal}(\beta 1-3)$ DGlcNAc( $\beta 1-3)$ DGal $(\beta 1-4) D G l c-O-R 1$, GSC-65 (Hasegawa et al., 1991); Sialyl-Lewis ${ }^{x}$-Cer, NeusAc ( $\left.\alpha 2-3\right)$ DGal $(\beta 1-4)$ [DFuc $(\alpha 1-3)$ ]DGlcNAc $(\beta 1-3)$ $\operatorname{DGal}(\beta 1-4) D G l c-0-R_{1}$, GSC-64 (Kameyama et al., 1991); Sialyl-Lacto-NtetraosylCer, NeusAc( $\alpha 2-3)$ DGal $(\beta 1-3) D G I c N A c(\beta 1-3) D G a l(\beta 1-4) D G l c-O$ $-\mathrm{R}_{1}$, GSC-30 (Kameyama et al., 1990); Sialyl-Lacto- $N$-neoterraosyl-Cer, Neus Ac( $\alpha 2-3)$ DGal $(\beta 1-4)$ DGlcNAc( $(\beta 1-3)$ DGal $(\beta 1-4)$ DGlc-O-R ,, GSC-31 (Kameyama et al., 1990); Sialyl-Sialyl-lactose-Cer, Neu5Ac( $\alpha 2-9)$ Nau5Ac$(\alpha 2-3)$ DGal $(\beta 1-4)$ DGlc-O-R, GSC-96 (Hasegawa et al., 1992c); Monosialoganglioside-GM,$\quad$ DGal $(\beta 1-3) D G a l N A c(\beta 1-4)[N e u 5 A c(\alpha 2-3)] D G a l(\beta 1-4)$ DGlc-Cer; Monosialoganglioside-GM, , DGalNAc $(\beta 1-4)$ [Neu5Ac( $(\alpha 2-3)]-$ $\operatorname{DGal}(\beta 1-4) D G l c-C e r ;$ Monosıaloganglioside-GM, Neu5Ac( $\alpha 2-3)$ DGal $(\beta 1-4)$ DGIc-Cer; Monosialoganglioside-GM ${ }_{3}$, NeusAc( $\left.\alpha 2-3\right)$ DGal $(\beta 1-4)$ DGlc-O-R , GSC-17 (Murase et al., 1989); 8-epi GM , GSC-50 (Hasegawa et al., 1992b); 9-deoxy $\mathrm{GM}_{3}$, GSC-51 (Hasegawa et al., 1992a); Sialyl-lactose-Cer, New5Ac( $\alpha 2-6)$ DGal $(\beta 1-4)$ DGlc-O-R, GSC-61 (Hasegawa et al., 1992d); 4-deoxy $\mathrm{GM}_{3}$, GSC-75 (Hasegawa et al., 1992a); 7-deoxy GM , GSC-76 (Hasegawa et al., 1992a); 8-deoxy GM, GSC-77 (Hasegawa et al., 1992a);

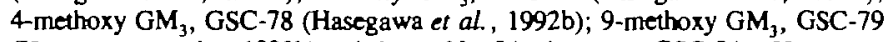
(Hasegawa et al., 1992b); 4-deoxy-NeuSAc-lactose, GSC-84 (Hasegawa et al., 1992a).

\section{FACS analysis of trypomastigotes}

Monoclonal antibody $3 \mathrm{C} 9$ ( $\mathrm{IgG1}$ ) anti-Ssp-3 was purified from ascitic flutds by DEAE-cellulose chromatography. Parasites $\left(2.5 \times 10^{\circ}\right)$ were washed with $0.2 \%$ DMEM-BSA, resuspended in $500 \mu$ l of $0.2 \%$ DMEM-BSA containing $5 \mu \mathrm{g} / \mathrm{ml}$ of the $3 \mathrm{C} 9$ antibody and incubated for $30 \mathrm{~min}$ on ice. The suspension was centrifuged, the pellet resuspended in $100 \mu \mathrm{l}$ of $0.2 \%$ DMEM-BSA and $900 \mu \mathrm{l}$ of $4 x_{0}$ paraformaldehyde in PBS added. After $60 \mathrm{~min}$ at $4^{\circ} \mathrm{C}$, the fixative was removed by centrifugation and the parasites washed twice with $1 \mathrm{ml}$ of cold $0.2 \%$ DMEM-BSA. The parasites were resuspended in $500 \mu \mathrm{l}$ DMEM-BSA and goat anti-mouse IgG conjugated with fluorescein isothiocyanate (FITC) (Bochringer Mannheim) added to a 1/50 dilution. After an incubation of $30 \mathrm{~min}$ at $4{ }^{\circ} \mathrm{C}$, the suspensions were centrifuged, washed with $0.2 \%$ DMEM-BSA, resuspended in $50 \mu$ l of PBS and post-fixed with $450 \mu$ of $4 \%$ paraformaldehyde. The mixtures were analysed on a Becton Dickinson FACScan. FACS analysis was performed on parasite samples of untreated BSA- and FBStrypomastigotes, on samples obtained after incubation of these parasites with different saccharides, or after mixing them with each other for 60 min at $37^{\circ} \mathrm{C}$.

\section{Cell adhesion assay}

L-Cells transfected with E-selectin cDNA were the gift of Dr T.Kishumoto (Boehringer Ingelheim, Ridgefield, CT) and were grown in freshly prepared GPT-selective medium [RPMI 1640 (Gibco BRL, Gaithersburg, MD), 10\% FBS, $0.1 \mathrm{mM}$ hypoxanthine, $16 \mu \mathrm{M}$ thymidine, $250 \mu \mathrm{g} / \mathrm{ml}$ xanthine, $5 \mu \mathrm{g} / \mathrm{ml}$ mycophenolıc acid]; parent L-cells were grown in RPMI 1640 supplemented with $10 \%$ FBS. Transfected and control cells were plated at a density of $4 \times 10^{4}$ cells/well in 6-well plates (Falcon 3046, Becton Dickinson, NJ) $24 \mathrm{~h}$ prior to the assay. Human neutrophils were purified from citrated human blood using Mono-Poly resolving medium (ICN Biomedicals, Flow Laboratories) according to the manufacturer's instructions. The isolated neutrophils were washed three times with DMEM and resuspended in $50 \mathrm{mM}$ DMEM-Pipes (pH 6.5). Cells at $8 \times 10^{6}$ cells/tube were treated with either 
$0.2 \mathrm{U} / \mathrm{ml}$ ssalidase (V.cholerae, protease-free, azide removed by dialysis, Bochringer Mannheim), punfied TS with lactose $(1 \mathrm{mM})$ or an equal volume of PBS. Neutrophils were incubated at $37^{\circ} \mathrm{C}$ for $90 \mathrm{~min}$, spun down and washed twice with DMEM.

L-Cell cultures were washed once with DMEM without FBS and co-incubated with $2 \mathrm{ml}$ of a suspension of neutrophils at $2 \times 10^{4} / \mathrm{ml}$. L-Cells and neutrophils were incubated for $60 \mathrm{~min}$ at $37^{\circ} \mathrm{C}$ on a rotary shaker, after which the medium was removed and the wells washed six times with DMEM without FBS. Rosetting of neutrophils around the adherent L-cells was evaluated microscopically and expressed as percent of L-cells with more than one neutrophil attached.

\section{Acknowledgements}

We thank Mr Ching Huang for expert technical assistance. This work was supported by grants from the MacArthur Foundation, the UNDP/World Bank/wHO Special Program for Research and Training in Tropical Diseases, Conselho Nacional de Desenvolvimento Cienufico e Tecnologico and Fundacao de Amparo a Pesquisa do Estado de Sao Paulo (Brazl) F.V. is a Research Assistant of the Belgian National Fund for Scientific Research (NFWO), L.P.C is a recipient of a grant from the Secretaria de Ciencia e Tecnologia (Programa RHAE), Brazil

\section{Abbreviations}

BSA, bovine serum albumin; DMEM, Dulbecco's modified Eagle's medium; FBS, fetal bovine serum; FITC, fluorescein isothiocyanate; mAb, monoclonal antubody, MU-Neu5Ac, 4'-methyl-umbelliferyl $\mathrm{N}$-acetyl neuramunc acid; Neu5Ac, $N$-acetyl-neuramınıc acıd; SA, stalıc acid, TS, trans-sialıdase

\section{References}

Affranchıno,J.L., Ibanez,C.F , Luquetti,A.O., Rassi,A., Reyes,M B., Macina,R.A., Aslund,L., Pettersson,U. and Frasch,A.C C. (1989) Identification of a Trypanosoma cruz antigen that is shed during the acute phase of Chagas' disease. Mol. Biochem. Parasitol., 34, 221-228

Andrews, N.W., Hong,K.-S., Robbıns, E S. and Nussenzweig,V. (1987) Stagespecific surface anugens expressed during the morphogenesis of vertebrate forms of Trypanosoma cruzi. Exp. Parasitol., 64, 474-484.

Corfield, A P and Schauer,R. (1982) Metabolism of sialic acids. In Schauer,R. (ed.), Cell Biology Monographs. Sialic Acids. Chemistry, Metabolssm and Function. Spnnger-Verlag, New York, pp. 197-261.

Cote,G. and Tao,B. (1990) Oligosaccharide synthesis by enzymatic transglycosylation. Glycoconjugate $J ., 7,145-162$

de Titto,E.H and Araujo,F G (1988) Serum neuraminidase activity and hematological alterations in acute human Chagas' disease. Clin Immunol. Immunopathol., 46, 157-161.

El Khadem,H. (1988) In Carbohydrate Chemistry-Monosaccharides and their Oligomers. Academic Press, San Diego, pp. $27-44$.

Foxall,C., Watson,S , Dowbenko,D., Fennie,C., Lasky,L., Kiso,M., Hasegawa,A., Asa,D. and Brandley,B. (1992) The three members of the selectin receptor family recognize a common carbohydrate epitope, the sialyl Lewis" oligosacchande. J. Cell Biol., 117, 895-902.

Frever, U., Schenkman,S. and Nussenzweig,V. (1992) Stage-specific expression and intracellular shedding of the cell surface specific trans-sialidase of Trypanosoma cruzi. Infect. Immun., 60, 2349-2360.

Garcia-Zapata,M., McGreevy,P. and Marsden,P. (1991) Chagas' disease. In Strickland,G. (ed.), Hunters' Tropical Medicine. W B.Saunders, Philadelphia, pp. 628-637.

Hasegawa,A., Hotta,K., Kameyama,A., Ishida,H. and Kiso,M. (1991) Total synthesis of sialyl $(\alpha 2-6)$ lactotetraosylceramide and sialyl $(\alpha 2-6)$ neolactotetraosylceramide. J. Carbohydr. Chem., 10, 439-459.

Hasegawa,A., Adachi,K., Toshida,M. and Kiso,M (1992a) Synthesis of a series of ganglioside $\mathrm{GM}_{3}$ analogs containing a deoxy-N-acetylneuraminic acid residue. Carbohydr. Res., 230, 273-288.

Hasegawa,A., Adachi,K., Yoshida,M. and Kuso,M. (1992b) Synthesis of ganglioside $\mathrm{GM}_{3}$ analogs containing the chemically modified sialic acids. J Carbahydr. Chem., 11, 95-116.

Hasegawa, A., Ogawa,H. and Kiso,M. (1992c) Synthesis of a position isomer of ganglioside $\mathrm{GD}_{3}$ having an $\alpha \mathrm{Neu} 5 \mathrm{Ac}(2-9) \alpha$ Neu5Ac linkage. Carbohydr. Res., 224, 185-192.

Hasegawa,A., Ogawa,M. and Kiso,M. (1992d) Synthesis of a ganglıoside $\mathrm{GM}_{3}$ postion isomer, $\mathrm{N}$-acetylneuraminosyl $(\alpha 2-6)$ lactosyl $(\beta 1-1)$ ceramide. Biosci. Biotech. Bioctiem., 56, 535-536.

Kahn, S , Colbert, T.G., Wallace,J.C., Hoagland.N.A. and Eisen,H (1991) The major $85-\mathrm{kDa}$ surface antigen of the mammalian-stage forms of
Trypanosoma cruza is a family of sialidases Proc. Natl. Acad. Sci. USA, 88, $4481-4485$

Kameyama,A., Ishıda,H , Kiso,M. and Hasegawa,A. (1990) Stereoselective synthesis of sialyl-lactotetraosylceramide and sialyl-neolactoretraosylceramide. Carbohydr. Res., 200, 269-285

Kameyama,A., Ishida,H., Kiso, M. and Hasegawa,A. (1991) Total synthesis of sialyl-Lewis. Carbohydr. Res., 209, cl-c4.

Meindl,P., Bodo,G., Palese,P., Schulman,J. and Tuppy,H. (1974) Inhibıtion of neuraminidase activity by derivatives of 2-deoxy-2,3-dehydro- $N$-acetylneuraminic acid. Virology, 58, 457-463.

Murase,T., Ishida,H., Kiso,M. and Hasegawa, A. (1989) A facile, regio- and stereo-selective synthesis of ganglioside $\mathrm{GM}_{3}$. Carbohydr. Res, 188 . $71-80$.

Parod,,A, Pollevick,G., Mautner,M., Buschiazzo,A., Sanchez,D. and Frasch,C. (1992) Identification of the genes coding for the trans-sialidase of Trypanosoma cruzr. EMBO J 11, 1705-1710.

Passaniti,A. and Hart,G.W. (1988) Cell surface sialylation and tumor metastasis. Metastatic potenual of B16 melanoma variants correlates with their relative numbers of specific penulumate oligosaccharide structures J. Biol. Chem., 263, 7591-7603.

Paulson,J, Prieels,J , Glasgow,L. and Hill,R. (1978) Sialyl- and fucosyltransferases in the biosynthesis of asparaginyl-linked olıgosacchandes in glycoproteins. Mutually exclusive glycosylation by $\beta$-galactoside $\alpha 2-6$ stalyltransferase and $N$-acetylglucosaminide $\alpha 1-3$ fucosyltransferase. J. Biol. Chem. 253, 5617-5624.

Pereira,M.E. (1983) A developmentally regulated neuraminidase activity in Trypanosoma cruzi. Science, 219, 1444-1446

Pollevick,G.D., Affranchino,J L , Frasch,A.C.C. and Sanchez,D.O. (1991) The complete sequence of a shed acute-phase antugen of Trypanosoma cruji Mol. Biochem. Parasiol., 47, 247-250

Previato,J.O., Andrade,A.F., Pessolani,M.C and Mendonca Previato,L (1985) Incorporation of sialic acid into Trypanosoma cruzi macromolecules: a proposal for a new metabolic route. Mol. Biochem. Parasitol., 16, 85-96

Reuter,G. and Schauer,R. (1988) Suggestions on the nomenclature of stalıc acids. Glycoconjugate J., 5, 133-135.

Roggentin,P , Rothe,B., Kaper,J.B., Galen,J., Lawrisuk,L, Vimr,E.R. and Schauer, $R$. (1989) Conserved sequences in bacterial and viral stalidases. Glycoconjugate J., 6, 349-353.

Russo,T., Thompson,J., Godoy, V. and Malamy,M. (1990) Cloning and expression of the Bacteroides fragilis TAL2480 neuraminidase gene, nanH, in $E$ coli. J. Bacteriol., 172, 2594-2600.

Schauer,R., Reuter,G., Muhlpfordt,H., Andrade,A.F. and Pereira,M.E (1983) The occurrence of $N$-acetyl- and $N$-glycolylneuraminic acid in Trypanosoma cruzi. Hoppe-Seyler's Z Physiol. Chem., 364, 1053-1057.

Schenkman,S., Man-Shiow,J., Har, G.W. and Nussenzweig, V. (1991a) A novel cell surface trans-sialidase of Trypanosoma cruzi generates a stagespecific epitope required for invasion of mammalian cells. Cell, 65 , $1117-1125$.

Schenkman,S., Robbins,E.S. and Nussenzweig,V. (1991b) Attachment of Trypanosoma cruzi to mammalian cells requires parasite energy, and invasion can be independent of the target cell cytoskeleton. Infect. Immun., 59, $645-654$

Schenkman, S., Kurosaki, T., Ravetch,J. and Nussenzweig,V. (1992a) Evidence for the participation of the Ssp-3 antigen in the invasion of non-phagocytic mammalian cells by Trypanosoma cruzi. J. Exp. Med., 175, 1635-1641.

Schenkman,S., Pontes de Carvalho,L. and Nussenzweig,V. (1992b) Trypanosoma cruzi trans-sialidase and neuraminidase activitues can be mediated by the same enzymes. J. Eq. Med., 175, 567-575.

Silva,L.H.P. and Nussenzweig,V. (1953) Sobre uma cepa de Trypanosoma cruzi altamente virulenta para o camundongo branco. Folia Clin. Biol., 20, 191-203.

Takle,G.B. and Cross,G.A.M. (1991) An 85-kilodalton surface antigen gene family of Trypanosoma cruzi encodes polypeptides homologous to bactenal neuraminidases. Mol. Biochem. Parasitol., 48, 185-198

Tyrrell,D., James, P , Rao,N., Foxall,C., Abbas, S., Dasgupta,F., Nashed,M. Hasegawa, A., Kiso,M., Asa,D., Kidd,J. and Brandley,B. (1991) Structural requirements for the carbohydrate ligand of E-selectin. Biochemistry, 88, 10372-10376.

Uemura,H., Schenkman,S., Nussenzweig,V and Eichinger,D. (1992) Only some members of a gene famuly in Trpanosoma cruzi encode proteins which express both trans-sialidase and neuraminidase activities $E M B O J$, in press.

Zingales,B., Carnol,C., de Lederkremer,R.M. and Coll,,W. (1987) Direct sialic acid transfer from a protein donor to glycolipids of trypomastugote forms of Trypanosoma cruzi. Mol. Biochem. Parasitol., 26, 135-144.

Received on July 10, 1992; accepted on September 7. 1992 